\title{
ARTIGO
}

\section{ANÁLISE DE VIABILIDADE DA UTILIZAÇÃO DO ÓLEO DE DENDÊ NA LUBRIFICAÇÃO AUTOMOTIVA ATRAVÉS DO ENSAIO PIN-ON-DISK ${ }^{1}$}

\author{
Erickson Fabiano Moura Sousa Silva ${ }^{2}$ \\ Sillas Oliveira Cezar \\ Aparecido Carlos Gonçalves \\ Paulo Roberto Rocha Matos Filho \\ Gabriel Alves Costa
}

\begin{abstract}
RESUMO
Alternativas que reduzam a dependência da matriz energética mundial aos derivados do petróleo são discutidas cada vez mais. Existe uma grande quantidade de dados acadêmicos relacionando consequências perniciosas ao meio ambiente devido a indústria de petróleo e seus componentes refinados. A substituição dos óleos a base mineral pela base vegetal é uma medida seguindo essa tendência. O óleo vegetal é uma substância biodegradável com a capacidade comprovada de ser decomposta em um intervalo de até um ano, o que faz com que seja um produto menos tóxico e agressivo ao meio ambiente do que os de base minerais. $\mathrm{O}$ óleo vegetal escolhido para esse trabalho foi o de dendê, por ser um óleo popularmente conhecido na culinária brasileira, principalmente baiana. É um dos óleos vegetais mais consumidos no mundo, atrás apenas dos óleos de soja e canola. O objetivo desse estudo foi comparar as propriedades e comportamentos do óleo mineral $15 \mathrm{w}-40$ com o óleo de dendê através de um ensaio PIN-ON-DISK com presença do filme de óleo. Após os ensaios, os óleos utilizados foram analisados através dos dados de espectrometria, ferrografia, viscosidade de Saybolt, monitor de partículas ferrosas e dos sinais coletados pelo software, gerados pelo tribômetro. Pelos resultados obtidos, observou-se que o lubrificante vegetal, óleo de dendê, tem grande potencial para ser usado na substituição do óleo mineral. Os dados apresentaram a real possibilidade da utilização do óleo livre de qualquer tipo de tratamento adicional a fim de torná-lo mais eficiente, como mistura de aditivos ou envelhecimento.
\end{abstract}

Palavras-chave: Tribologia. Lubrificante vegetal. Desgaste.

\section{INTRODUÇÃO}

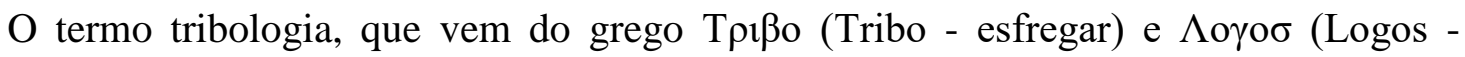
estudo), de forma que uma tradução literal significa 'Estudo do Atrito' ou a ciência que estuda

\footnotetext{
${ }^{1}$ Como citar este artigo: SILVA, Erickson Fabiano Moura Sousa; CEZAR, Sillas Oliveira; GONÇALVES, Aparecido Carlos; FILHO MATOS, Paulo Roberto Rocha; COSTA, Gabriel Alves. Análise de viabilidade da utilização do óleo de dendê na lubrificação automotiva através do ensaio pin-on-disk. ForScience: revista científica do IFMG, Formiga, v. 7, n. 2, e00636, jul./dez. 2019. DOI: 10.29069/forscience.2019v7n2.e636.
}

\footnotetext{
${ }^{2}$ Autor para correspondência: Erickson Fabiano Moura Sousa Silva, e-mail: efmssilva @uesc.br.
} 
o Atrito. Este termo foi utilizado oficialmente pela primeira vez em 1966, na Inglaterra, em um relatório feito por H. Peter Jost para o comitê do departamento de educação e ciência. Segundo Jost a tribologia é definida como "A ciência e a tecnologia da interação entre superfícies com movimento relativo e dos assuntos e práticas relacionadas" (RADI et al., 2007).

Jost foi pioneiro no estudo de impactos econômicos devido à utilização dos conhecimentos de tribologia. Em seu relatório, as estimativas de reduções de gastos apresentadas mediante o uso do conhecimento já existente poderiam reduzir as perdas por desgaste em até 20\% (JOST, 1966). Tendo tais informações em vista, as análises de perdas por desgaste são de grande importância no aspecto ambiental.

De acordo com Radi (2007), se tomar como exemplo o funcionamento de um automóvel que pode ter cerca de $15 \%$ em perdas por atrito, uma melhoria de $20 \%$ significaria em uma economia de 300 milhões de reais por ano, que são investidos para uma redução de 37.500 toneladas de $\mathrm{CO}_{2}$ emitidos anualmente para atmosfera, levando em consideração apenas a cidade de São Paulo.

Apesar da palavra ser relativamente nova, a tribologia se dedica, ao estudo do desgaste, do atrito e, por conseguinte, da lubrificação, como forma tradicional de minimizálos. Apoia-se em áreas como a mecânica, física, química e ciências dos materiais, não envolvendo, portando, nenhum conhecimento novo (SINATORA, 2005). A invenção da roda ilustra bem a preocupação do homem em reduzir o atrito nos movimentos de rotação e translação, sendo esta anterior a qualquer registro histórico existente.

Os fenômenos tribológicos não estão restritos às máquinas, seus mancais ou a inovações tecnológicas, a própria habilidade de andar é decorrente da ação do atrito entre os pés e o chão. Logo o atrito é algo desejado em algumas situações como esquiar, surfar, correr, frenar algo em movimento, de modo que os efeitos tribológicos tiveram uma grande influência no processo da evolução humana (STOETERAU, 2004).

\section{DESENVOLVIMENTO}

Neste tópico abordaremos todos os conteúdos teóricos utilizados ao longo do experimento. Essa revisão tem como objetivo ajudar o leitor a ter uma melhor compreensão e entendimento dos procedimentos experimentais e seus resultados. 


\subsection{REVISÃO DE LITERATURA}

\subsubsection{Lubrificantes}

São materiais capazes de alterar as respostas tribológicas do sistema (PERSSON, 1998 apud MARU, 2003). Através de uma película de fluido interposta entre duas superfícies atritantes em movimento relativo é capaz de reduzir o atrito e ruído com o mínimo de aquecimento e desgaste (ACHCAR, 2015).

Eles podem ser classificados de acordo com seu estado físico: lubrificantes líquidos são os mais empregados e possui propriedades de baixa resistência a cisalhamento e alta resistência a compressão, como por exemplo óleos derivados do petróleo, no qual é essencialmente incompressível aos níveis de tensão de compressão, porém cisalha com facilidade, tornando o material mais fraco na interface. Sua baixa resistência ao cisalhamento reduz o coeficiente de atrito (NORTON, 2013). Esses podem ser subdivididos em: óleos minerais puros, óleos graxos, óleos compostos, óleos aditivados e óleos sintéticos (SEDUC, 2011). Para fins comerciais são adicionados aditivos que melhoram e/ou adicionam propriedades importantes para comercialização, como por exemplo a característica de Pressão Extrema (PE), utilizado para reduzir atrito entre pares engrenados, no qual adicionam ácidos graxos ou outros compostos ao óleo para atacar o metal quimicamente e formar uma camada contaminante que protege e reduz o atrito mesmo quando o filme de óleo é espremido da superfície pelas altas cargas de contato (NORTON, 2013).

Para a lubrificação sólida há basicamente dois tipos de materiais que exibem tensões de cisalhamento baixas, como o grafite e o dissulfeto de molibdênio (MOS2), que são adicionados à interface, e camadas como fosfatos, óxidos ou sulfetos que são produzidas nas superfícies dos materiais. Os materiais de grafite e MOS2 são tipicamente fornecidos em forma de pó e podem ser levados à interface em um aglutinador de graxa de petróleo ou outro material. Eles têm a vantagem de possuírem menor coeficiente de atrito e resistência a altas temperaturas (NORTON, 2013).

\subsubsection{Tipos de lubrificantes}

Os primeiros lubrificantes eram de origem animal ou vegetal e posteriormente foram substituídos por óleos minerais, que além de serem mais baratos, não sofrem hidrólise nem se 
tornam ácidos ou corrosivos pelo uso, tornando pouco comum seu uso em máquinas modernas, principalmente em altas temperaturas (SEDUC, 2011). Sua vantagem é a capacidade de aderência a superfícies metálicas, devida presença de ácidos graxos livres em pequena quantidade. Já sua principal desvantagem está na péssima resistência a oxidação, tornando-o pouco eficiente para a lubrificação.

Os óleos compostos são constituídos de misturas de óleos minerais e graxos. A percentagem de óleo graxo é pequena, variando de acordo com a finalidade do óleo (SEDUC, 2011).

Os óleos sintéticos são provenientes da indústria petroquímica. "Criados" em laboratório por processo de polimerização, especialmente para suportar condições bastante adversas, são os melhores lubrificantes, e de maiores custos. Devido ao seu alto custo, se aplica aos locais onde os óleos convencionais não podem ser utilizados. Alguns outros líquidos são empregados como lubrificantes, dado a impossibilidade de se utilizarem quaisquer dos tipos mencionados. A água, algumas vezes empregada, possui propriedades lubrificantes reduzidas, além de ter ação corrosiva sobre os metais. Os pastosos, comumente chamados graxas, são empregados onde os lubrificantes líquidos não executam suas funções satisfatoriamente. As graxas podem ser subdivididas em: graxas de sabão metálico, graxas sintéticas, graxas à base de argila, graxas betuminosas e graxas para processo (SEDUC, 2011).

\subsubsection{Biolubrificantes}

Um biolubrificante significa um lubrificante que é biodegradável. Por sua vez, uma substância ser biodegradável significa que a mesma tem a capacidade comprovada de ser decomposta, em um intervalo de até 1 ano, por meio de processos biológicos naturais em terra carbonácea, água ou dióxido de carbono (WHITBY, 2005).

Em termos gerais, biodegradabilidade significa a tendência de um lubrificante ser metabolizado por microrganismos em até 1 ano. Quando ela é completa, significa que o óleo retornou essencialmente à natureza, e quando é dita parcial, indica que um ou mais componentes não são degradáveis (SILVA, 2012). A biodegradabilidade resulta em auto decomposição por meio de microrganismos em $\mathrm{CO}_{2}$ e água. A forma pela qual os microrganismos executam isto depende largamente das suas estruturas. Os óleos vegetais são tipicamente $99 \%$ biodegradáveis, caindo, usualmente, para 90-98\% após a mistura com 
aditivos. Por outro lado, a biodegradabilidade dos óleos minerais é de apenas 20\% (BÍROVÁ; PAVLOVIčOVÁ; CVENROŁ, 2002).

Durante anos ouve tentativas de definir o termo biodegradabilidade e isto resultou em um atraso no desenvolvimento de padrões. Além disso, a ênfase em compatibilidade ambiental significava menos ênfase nos aspectos econômicos destes produtos e, em alguns casos, no seu desempenho. Como resultado, os primeiros produtos apresentaram custo elevado e/ou baixo desempenho e mesmo assim, os mesmos encontravam um nicho de mercado. No final dos anos 90, entretanto, muitas companhias americanas reduziram ou eliminaram os seus projetos "verdes" e as pesquisas continuaram apenas em laboratórios acadêmicos e governamentais (SILVA, 2012).

A tecnologia inicial para biolubrificantes foi baseada em óleos vegetais que foram submetidos a mínimos tratamentos químicos e aos quais foram adicionados aditivos para aumento de desempenho (SILVA, 2012). Os óleos de base vegetal possuem algumas características consideradas excelentes como, por exemplo:

- Índice de viscosidade (IV) elevado;

- Baixa volatilidade;

- São mais biodegradáveis que os óleos minerais;

- São livres de compostos de enxofre;

- Apresentam excelente lubricidade;

- Não apresentam toxicidade;

- Possuem elevado ponto de fulgor.

Porém, os óleos vegetais apresentam menor estabilidade oxidativa, gerando compostos insolúveis, aumentando a viscosidade e a acidez do produto. Estes processos de oxidação podem ter um efeito significativamente negativo sobre o desempenho da lubrificação (ALVES, 2014). No entanto, o uso de aditivos antioxidantes pode retardar ou prevenir esse processo, por proteger o lubrificante da degradação oxidativa e ao mesmo tempo permitir que o óleo satisfaça os requisitos exigidos pela indústria (QUINCHIA et al., 2011 apud ALVES, 2014). Além da melhora na composição química dos óleos vegetais com relação a estabilidade térmica e oxidativa, há uma gama enorme de pesquisas dedicadas a melhorar o desempenho dos óleos vegetais em aplicações específicas, utilizando diferentes tipos de 
aditivos e submetendo-os a testes de atrito e desgaste sobre condições controladas, por meio do uso de tribômetros (ALVES, 2014).

\section{a) Propriedades dos lubrificantes}

A principal função dos lubrificantes é minimizar fricção, desgaste, corrosão e formação de depósitos em vários sistemas mecânicos durante a sua operação. Para se atingir as características desejadas de um óleo lubrificante, realizam-se análises físico-químicas que permitem fazer uma pré-avaliação de seu desempenho (ACHCAR, 2015). Desta forma, a qualidade do lubrificante depende de várias propriedades tais como viscosidade, fluidez, lubricidade, estabilidade termo-oxidativa, ponto de fulgor, densidade e solvência para aditivos (SILVA, 2012). Algumas destas análises não refletem as condições encontradas na prática, mas são métodos empíricos que fornecem resultados comparativos de grande valia, quando associados aos métodos científicos desenvolvidos em laboratórios (ACHCAR, 2015).

\section{b) Viscosidade}

A viscosidade é uma medida da resistência de um fluido ao cisalhamento. Ela varia inversamente com a temperatura e diretamente com a pressão, ambos de maneira não linear. Isto significa que à medida que a temperatura do óleo aumenta, ele se torna menos viscoso, com a diminuição da temperatura, o óleo torna-se mais espesso, ou mais viscoso. Ela pode ser expressa tanto como uma viscosidade absoluta $\eta$ quanto como uma viscosidade cinemática $v$. Podem ser relacionadas pela massa especifica $\rho$, como expressa na Equação (1):

$$
\eta=v \rho
$$

A medição da viscosidade cinemática é feita de forma experimental um viscosímetro que pode ser rotacional ou de capilaridade. Um viscosímetro de capilaridade mede a taxa de fluxo do fluido através de um tubo capilar em uma temperatura particular, tipicamente $40 \mathrm{ou}$ $100^{\circ} \mathrm{C}$. Um viscosímetro rotacional mede o torque e a velocidade de rotação de um eixo vertical ou cone movendo-se dentro de um mancal com seu êmbolo concêntrico preenchido com o fluido de teste à temperatura de teste (NORTON, 2013). Logo, sempre que se referir a um valor que representa a viscosidade de um óleo, deve-se referir também à temperatura na qual ela foi medida, para que haja parâmetros para comparações (ACHCAR, 2015). 
Os cálculos de pressão de lubrificante e fluxos dentro de mancais possuem como parâmetro a medida de viscosidade absoluta, determinada de acordo com a Equação (1) pela medida da viscosidade cinemática (NORTON, 2013).

O lubrificante deve ser suficientemente viscoso para manter uma película protetora entre as peças em movimento relativo e também, não ser tão viscoso que ofereça resistência excessiva ao movimento entre as peças, portanto a viscosidade é uma das propriedades mais importantes na escolha do lubrificante (ACHCAR, 2015).

\section{c) Índice de viscosidade}

O índice de viscosidade (IV) é um número adimensional utilizado para caracterizar a variação da viscosidade cinemática de um produto derivado do petróleo com a temperatura. Quanto mais alto é o índice, mais estável é sua viscosidade com a variação da temperatura, com pode ser observado na Figura 1. Esse índice é calculado, segundo American Society for Testing and Materials (ASTM) DS 39B, descrito na Equação (2):

$$
I V=\left(\frac{L-U}{L-H}\right) \times 100
$$

Onde:

$\mathrm{L}=$ viscosidade cinemática a $40^{\circ} \mathrm{C}$ do óleo de referência com $\mathrm{IV}=0$ e a viscosidade cinemática a $100{ }^{\circ} \mathrm{C}$ equivalente ao óleo sendo avaliado;

$\mathrm{H}=$ viscosidade cinemática a $40{ }^{\circ} \mathrm{C}$ do óleo de referência com $\mathrm{IV}=100$ e viscosidade cinemática a $100{ }^{\circ} \mathrm{C}$ equivalente ao óleo sendo avaliado;

$\mathrm{U}=$ viscosidade cinemática a $40{ }^{\circ} \mathrm{C}$ do óleo sendo avaliado;

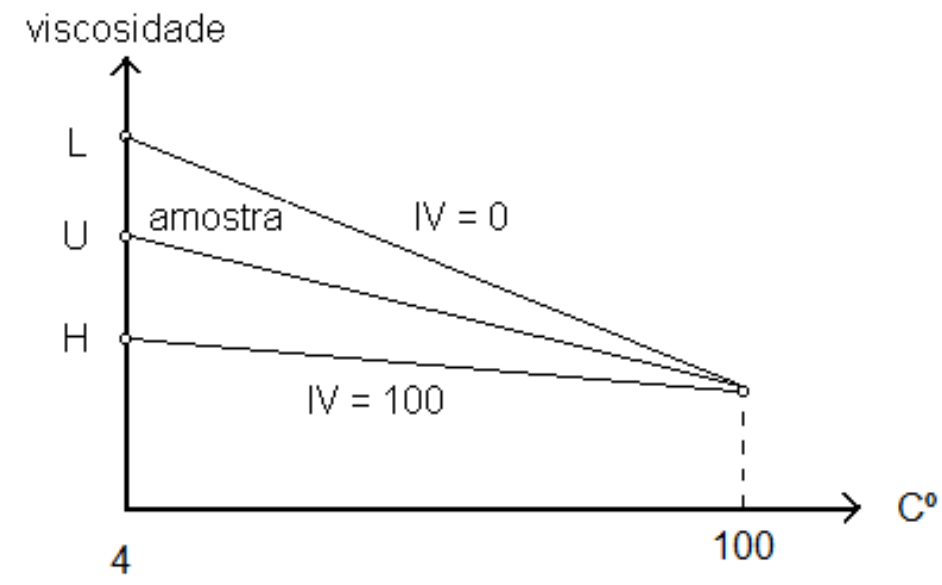

Figura 1- Parâmetros de referência para cálculo de IV Fonte: Análise Física de Óleos Lubrificantes. 
Os valores arranjados em Laboratório são adjuntos a unidades técnicas de medida de viscosidade (Centistokes, Segundos Saybolt, Centipoise) que a maior parte do público consumidor desconhece. Por sua vez, a Society of Automotive Engineers (SAE), criou um critério de classificação que teve consentimento generalizado pelos fabricantes de veículos e de lubrificantes. Esta classificação é feita associando-se um número puro à viscosidade determinada em laboratório, neste, quanto maior o número, maior será a viscosidade. A classificação SAE divide os óleos lubrificantes em dois grupos:

\section{d) Óleos de "grau de inverno"}

Óleos que aprovem uma fácil e rápida movimentação mesmo em condições de frio rígido ou na partida a frio do motor sua viscosidade é medida a baixas temperaturas e tem a letra W que significa winter (inverno em inglês), seguindo de um número de classificação. Os testes para esses óleos levam em consideração a resistência que o mesmo dará na partida a frio do motor e a facilidade de bombeamento e circulação em baixas temperaturas (SOUZA, 2014).

\section{e) Óleos de "grau de verão"}

São óleos que trabalham em altas temperaturas, sem o rompimento de seu filme lubrificante, pois quanto mais quente o óleo, menos viscoso ele se apresenta. $\mathrm{O}$ óleo de grau de verão tem sua viscosidade medida a altas temperaturas e não possuem a letra $\mathrm{W}$. Os testes desses óleos verificam a operabilidade do lubrificante em altas temperaturas, ou seja, a sua competência em oferecer proteção em regimes extremos (SILVEIRA; MACIEL; MOURA, 2004).

Existem óleos que, ao mesmo tempo, atendem a estas duas exigências. É o caso dos Óleos Multiviscosos, cuja classificação reúne coeficientes de óleos de inverno e de verão. Estes números que aparecem nas embalagens dos óleos lubrificantes automotivos (30, 40, 20W/40, etc.) correspondem à classificação da SAE, que se baseia na viscosidade dos óleos a temperatura de $100{ }^{\circ} \mathrm{C}$ e $40{ }^{\circ} \mathrm{C}$ (SILVEIRA; MACIEL; MOURA, 2004), apresentando duas escalas:

- $0 \mathrm{~W}$ até $25 \mathrm{~W}$ - Escala de baixa temperatura.

- 25W até $60 \mathrm{~W}$ - Escala de alta temperatura. 
Nas Tabelas 1 e 2 estão estimadas as viscosidades dinâmicas dos óleos lubrificantes SAE 5W20 e 5W40, para as temperaturas de 10, 50, 100 e $150^{\circ} \mathrm{C}$, com base no trabalho de Canciam (2013).

Tabela 1 -Valores estimados da viscosidade dinâmica para o lubrificante SAE 5W20

\begin{tabular}{cc}
\hline $\begin{array}{c}\text { Temperatura } \\
\left({ }^{\circ} \mathrm{C}\right)\end{array}$ & $\begin{array}{c}\text { Viscosidade dinâmica } \\
\left(.10^{-2} \mathrm{~Pa} . \mathrm{s}\right)\end{array}$ \\
\hline 10 & 19,0041 \\
50 & 3,0015 \\
100 & 0,7255 \\
150 & 0,2891
\end{tabular}

Fonte: Adaptado de Efeito da temperatura na viscosidade dinâmica dos óleos lubrificantes SAE 5w20, SAE 5w30 e SAE 5w40.

Tabela 2 - Valores estimados da viscosidade dinâmica para o lubrificante SAE 5W40

\begin{tabular}{cc}
$\begin{array}{c}\text { Temperatura } \\
\left({ }^{\circ} \mathrm{C}\right)\end{array}$ & $\begin{array}{c}\text { Viscosidade dinâmica } \\
\left(.10^{-2} \mathrm{~Pa} . \mathrm{s}\right)\end{array}$ \\
\hline 10 & 20,1991 \\
50 & 3,6737 \\
100 & 1,0196 \\
150 & 0,4503
\end{tabular}

Fonte: Adaptado de Efeito da temperatura na viscosidade dinâmica dos óleos lubrificantes SAE 5w20, SAE 5w30 e SAE 5w40.

Como pode-se observar nas tabelas apresentadas, quando o óleo possui o mesmo grau de inverno $(5 \mathrm{~W})$, para baixas temperaturas, os valores da viscosidade dinâmica estão relativamente próximos, mas à medida que a temperatura aumenta, a viscosidade do óleo que tem o grau de verão maior (40), tende a aumentar.

\section{f) Óleos minerais}

São usados como lubrificantes com uma adequada viscosidade, originados de petróleos crus, produzidos por meio de uma combinação de aditivos e óleos básicos obtidos pelo refino do petróleo. Eles não são tão desenvolvidos quanto os sintéticos e semissintéticos, apesar de auxiliar a anos os motores de funcionamento a diesel e gasolina (TEXACO, 2015). É um produto de menor custo, produzido em grandes quantidades e podem se distinguir em três tipos:

\section{g) Óleo mineral de base parafínico}


São ligas relativamente estáveis e resistentes que não podem ser modificadas facilmente por influências químicas. Sendo assim as parafinas tendem a não oxidar em temperaturas ambientes ou levemente elevadas. Contêm em sua composição química hidrocarbonetos de parafina em maior proporção, demonstram uma menor densidade sendo utilizados principalmente na elaboração de lubrificantes automotivos, por apresentar um melhor comportamento da viscosidade frente a variações de temperatura. Sua grande desvantagem é seu comportamento a baixas temperaturas, onde as parafinas tendem a sedimentar-se (TEXACO, 2015).

\section{h) Óleo mineral de base naftênico}

Os óleos básicos naftênicos são utilizados na fabricação de óleos isolantes para transformadores, graxas lubrificantes, fluidos de corte, óleos para compressores e óleos para amortecedores, podendo também ser utilizados como plastificantes de borracha (PETROBRAS). Os naftênicos em geral são usados, quando é necessário produzir lubrificantes para baixas temperaturas e possuem como principal desvantagem incompatibilidade com materiais sintéticos e elastômeros (TEXACO, 2015).

\section{i) Óleo mineral de base misto}

Refere-se a mistura dos óleos minerais com o de base naftênico ou parafínico em quantidades variadas. Possui diversas aplicações industriais como o óleo para refrigeração e isolamento de transformadores elétricos de potência, transporte e armazenagem de metais alcalinos. Esse tipo de óleo também pode ser usado para questões cosméticas e medicinais como laxantes, hidratantes, lubrificantes etc (TEXACO, 2015).

\section{j) Óleos vegetais}

A sociedade globalizada vem debatendo com o propósito de identificar alternativas que diminuam a utilização da matriz energética a base dos derivados do petróleo, dando espaço cada vez maior ao processamento de óleos vegetais e gorduras animais para a obtenção de biocombustíveis e biolubrificantes (MELO, 2010). 
O óleo vegetal é uma gordura extraída, geralmente das sementes, de plantas formada por triglicerídeos e apesar da recente ênfase nesse assunto nos dias atuais, a utilização do óleo pelo homem é tão antiga quanto à própria civilização.

Sabe-se que há mais de 6 mil anos o homem utilizava o óleo de oliva. Povos da Mesopotâmia usavam o óleo como protetor do frio, quando estes untavam seus corpos com ele (CAMPESTRE, 2016) e ao longo da história o homem foi encontrando, além da alimentação, as mais diversas aplicações para os óleos, como iluminação, calefação, aquecimento e lubrificação.

A disponibilidade de matéria prima de origem vegetal para a produção de biolubrificantes e biodiesel é variável, de acordo com a região do país, destacando as regiões Norte e Nordeste pelas suas variedades (OSAKI; BATALHA, 2011).

A viabilidade de cada oleaginosa para produção de biolubrificantes e biodiesel dependera da sua competitividade técnica, econômica e socioambiental, sazonalidade, produtividade por unidade de área, sistemas produtivos, entre outros fatores (RAMOS et al., 2017).

Os óleos vegetais em geral estão muito ligados a indústria alimentícia e a de cosméticos, sendo largamente produzidos nesses setores. Dentre esses se destacam os óleos de soja, canola, girassol, mamona, oliva, amendoim, dendê, dentre tantos outros (ARAÚJO, 2015).

\section{k) Óleo de dendê}

Entre as oleaginosas cultivadas, o dendezeiro (Elaeis guineenses Jacq.) ou palma como é conhecido, é a planta que apresenta a maior produtividade por área cultivada, produz em média, 10 vezes mais óleo do que a soja, sendo esses resultados possíveis em quase toda a região Amazônica (HENKES; LEBID, 2015).

É um óleo popularmente conhecido nas culinárias brasileira, principalmente baiana, e angolana sendo, no mundo, um dos mais consumidos atrás apenas dos óleos de soja e canola. Indispensável na cozinha afro-brasileira é utilizado em pratos como caruru, vatapá, acarajé, bobó de camarão, abará, entre outros.

O óleo de dendê está entre os mais qualificados para produção do biodiesel, devido sua composição, alta produtividade, baixo custo, produção distribuída ao longo de todo o ano, podendo ser cultivado em áreas distintas, sem comprometer os outros cultivos alimentares 
(HENKES; LEBID, 2015). O Pará é a região do Brasil que mais se cultiva a palmeira e um dos que mais investe em tecnologia e pesquisa no óleo de dendê, principalmente na área de biodiesel.

\subsection{MATERIAL E MÉTODOS}

As amostras de latão foram usinadas com a ajuda do torno Universal, aplicando um furo central e um chanfro de ambos lados da amostra. Esse furo com o auxílio do chanfro foi feito para que as amostras pudessem ser fixadas no tribômetro para a realização dos testes. Para um maior aproveitamento das amostras, registradas na Figura 2, esta foi usinada e preparada para poder ser utilizada de ambos os lados.

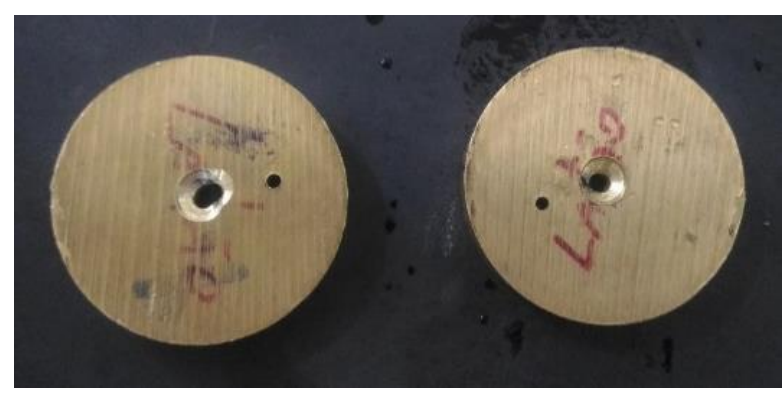

Figura 2- Amostras usinadas Fonte: Autores (2019).

Após a perfuração de fixação do disco, este foi polido com o objetivo de diminuir sua rugosidade ao máximo para uma melhor observação dos resultados posteriores como pode ser observado na Figura 3. Para que esses não sofressem problemas com o coeficiente de atrito inicial, fez-se necessário que todas as faces das amostras tivessem rugosidades iguais ou próximas, e dentro do padrão de rugosidades para polimento.

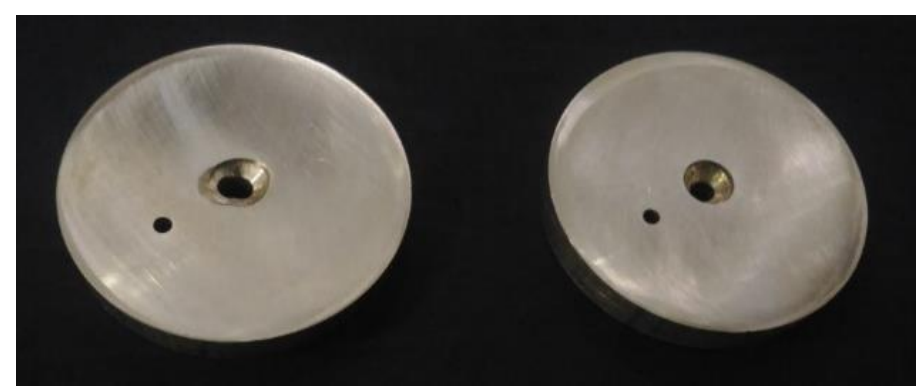

Figura 3 - Amostras 1 e 2 após polimento Fonte: Autores (2019). 
Após o polimento, o disco de bronze foi avaliado quanto a sua rugosidade, verificando se está dentro das especificações desejadas.

Foram feitos 3 diferentes tipos de teste. Os ensaios foram divididos em 3 partes:

- utilizando o óleo mineral como lubrificante (30ml);

- utilizando o óleo vegetal como lubrificante (30ml);

- sem a utilização de lubrificante.

O óleo mineral utilizado no experimento foi o Shell Helix HX5 (15w-40), por se tratar de um óleo comumente utilizado nos carros de passeio. Para o óleo vegetal utilizou-se o óleo de dendê, por se tratar de um dos óleos mais utilizados no mundo e ser muito conhecido da culinária baiana.

Cada ensaio simulou um percurso de $2 \mathrm{~km}$, onde o raio utilizado nos percursos do pino sobre os discos eram de $22 \mathrm{~mm}$. A força aplicada sobre a peça se manteve constante e de valor correspondente a 100N, assim como sua velocidade de rotação com o valor de $300 \mathrm{rpm}$.

A cada início e término de ensaio, as amostras foram pesadas em uma balança de precisão afim de se medir a quantidade de massa perdida durante o processo de desgaste. Os resultados visuais obtidos nas amostras após os testes realizados podem ser observados na Figura 4.
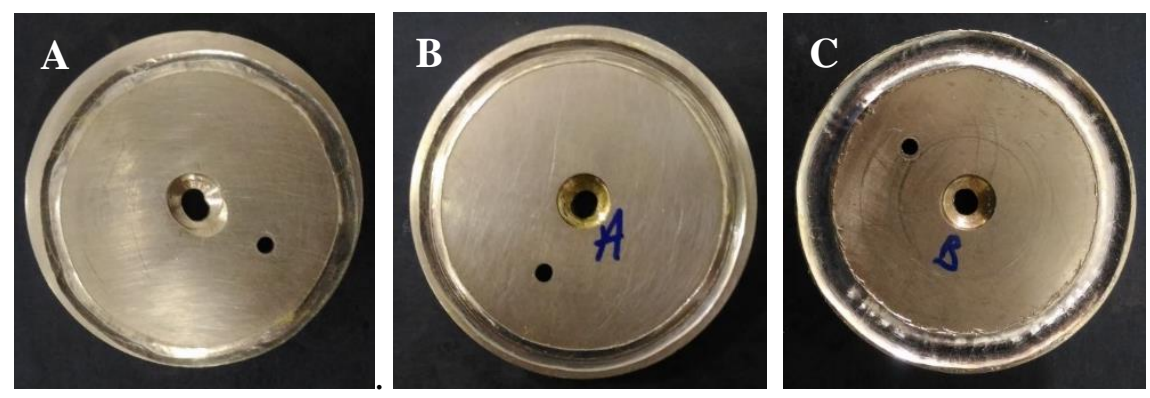

Figura 4 - A) Resultado na amostra para o teste com óleo mineral; B) Resultado na amostra para o teste com óleo vegetal; C) Resultado na amostra para o teste sem lubrificante Fonte: Autores (2019).

Após a realização dos testes PIN-ON-DISK, fez-se os testes da viscosidade, utilizando o Viscosímetro Saybolt; depositador rotativo de partículas (RPD - Rotary Particle Depositor); microscópio óptico (ou ferroscópio) e do monitor de Partículas Ferrosas (PQA - Particle Quantifier Analisys). 


\subsection{RESULTADOS E DISCUSSÕES}

Com os dados obtidos das Tabelas 3 e 4 pode-se analisar as perdas de massas observadas em cada um dos testes realizados. Observa-se que a amostra submetida ao teste com o óleo mineral sofreu uma menor perda de massa que a amostra utilizando o óleo vegetal. Comparando-se a quantidade de massa perdida nos testes dos lubrificantes, percebe-se uma maior perda de massa total, de uma amostra, quando se muda o lubrificante mineral para o vegetal.

Tabela 3 - Analise de perda de massa para o teste com óleo mineral

\begin{tabular}{ccc}
\hline & Antes do teste & Após o teste \\
\hline Media do peso & 128,8239 & 128,3655 \\
Perda em $(\mathrm{g})$ & ----------- & 0,4584 \\
Perda em $(\%)$ & ---------- & 0,36 \\
\hline Fonte: Autores (2019). &
\end{tabular}

Tabela 4 - Analise de perda de massa para o teste com óleo vegetal

\begin{tabular}{ccc}
\hline & Antes do teste & Após o teste \\
\hline Media do peso & 133,258 & 132,6914 \\
Perda em $(\mathrm{g})$ & ---------- & 0,5667 \\
Perda em $(\%)$ & ---------- & 0,43 \\
\hline
\end{tabular}

Fonte: Autores (2019).

A partir da captura dos sinais do hardware do tribômetro foi possível analisar graficamente parâmetros como a força aplicada ao longo do eixo $\mathrm{Z}$, posição do eixo $\mathrm{Z}$ e coeficiente de atrito.

$\mathrm{Na}$ força aplicada ao longo do eixo $\mathrm{Z}$ a variação da aplicação desta na amostra, foi 8 vezes menor para o teste com o óleo lubrificante mineral, quando comparado com os demais testes. Por sua vez, o lubrificante vegetal, a força aplicada ao longo do eixo z teve variação semelhante à do teste sem lubrificante, chegando a ser levemente superior, como se pode observar na Figura 5. 
(a)

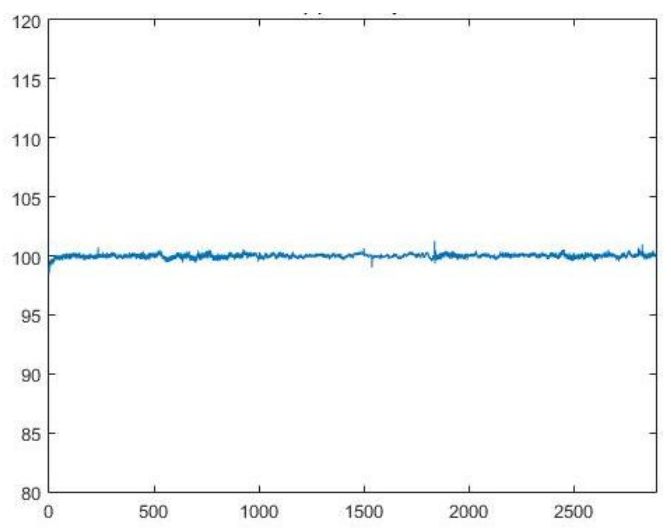

(b)

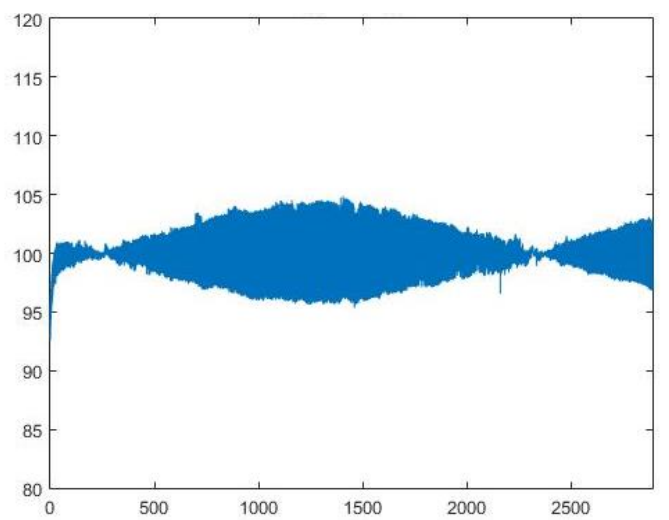

(c)

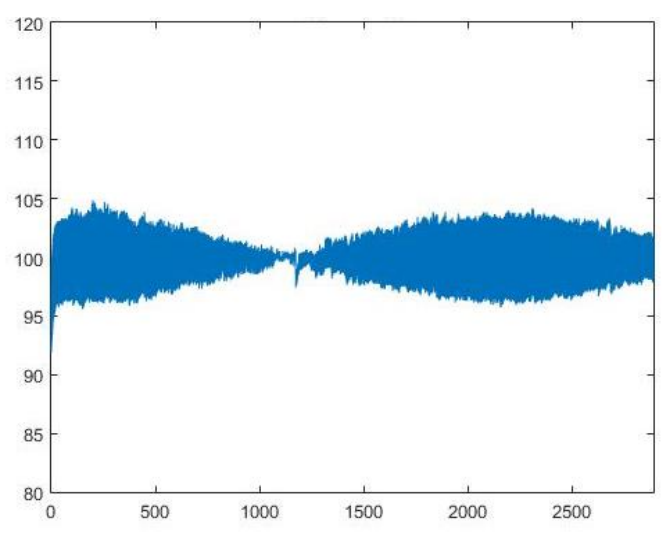

Figura 5 - Força aplicada em Z pelo tempo, para o teste com óleo mineral (a), vegetal (b) e sem lubrificante (c) Fonte: Autores (2019).

Para a posição do eixo Z, observou-se que a profundidade alcançada pela haste do tribômetro e como era de se esperar, é proporcional a eficiência do lubrificante utilizado. Logo, quanto menos eficiente, maior o desgaste sobre a peça. Na Figura 6 fica nítido que o teste com o lubrificante vegetal apresentou uma redução significativa no desgaste da peça quando comparada com o teste sem a presença do lubrificante. Quando comparado ao teste com o lubrificante mineral, o óleo vegetal se mostrou promissor, já que os resultados de ambos foram próximos. 
(a)

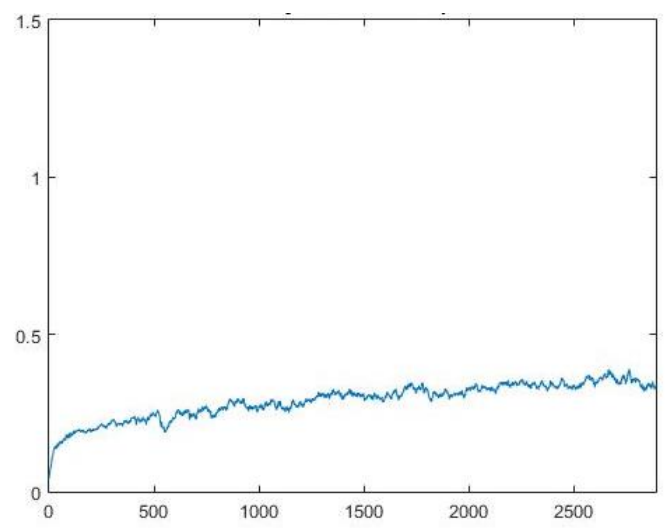

(b)

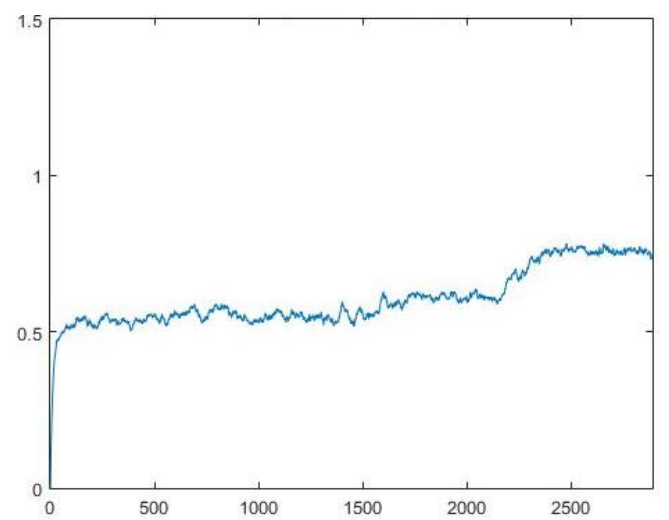

(c)

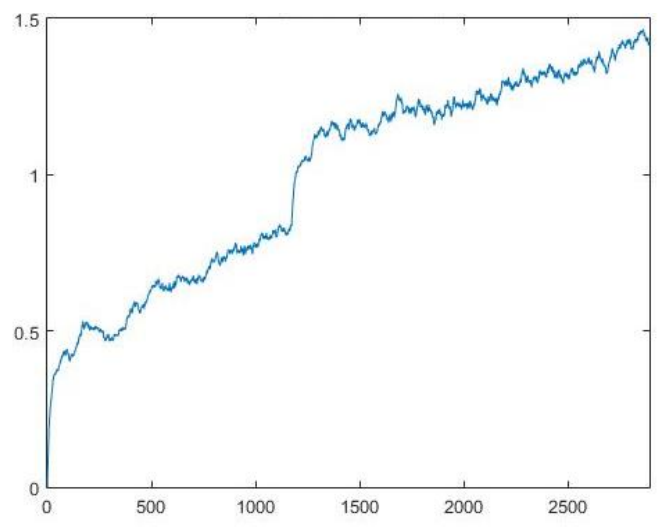

Figura 6 - Posição do eixo Z pelo tempo, para o teste com óleo mineral (a), vegetal (b) e sem lubrificante (c) Fonte: Autores (2019).

Analisando os coeficientes de atrito dos testes, foi possível observar que o lubrificante mineral e o vegetal trabalharam dentro de valores muito próximos após os 2000s de teste. Depois de ultrapassados os 2000s de teste para o óleo vegetal, o comportamento do coeficiente de atrito passa a sofrer uma variância muito maior em sua faixa de trabalho, chegando muito próximo ao comportamento no teste sem lubrificante, como se pode observar na Figura 7. Essa diferença do coeficiente após os 2000s pode ser atribuída ao fato do lubrificante vegetal não possuir nenhum aditivo, de modo que a película lubrificante sobre a peça se desprenda ao decorrer do tempo. 
(a)

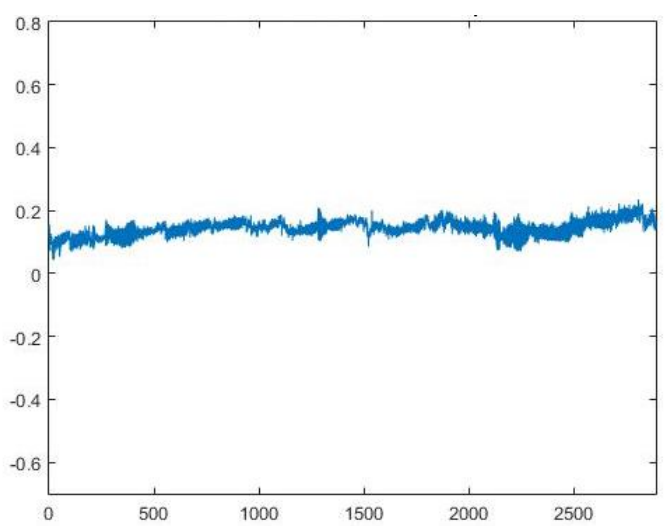

(b)

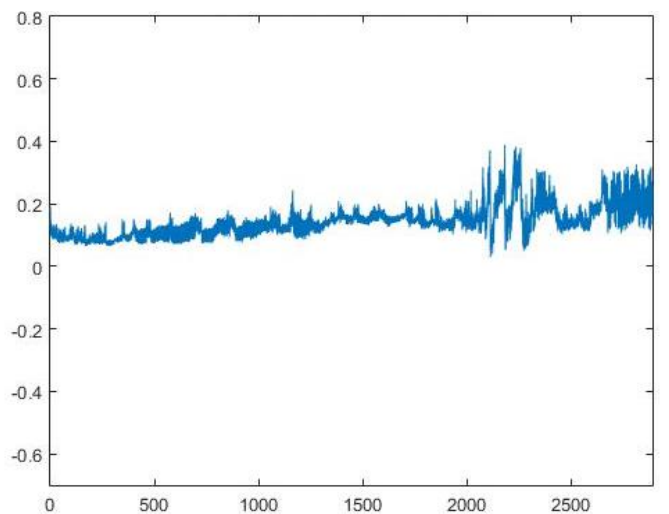

(c)

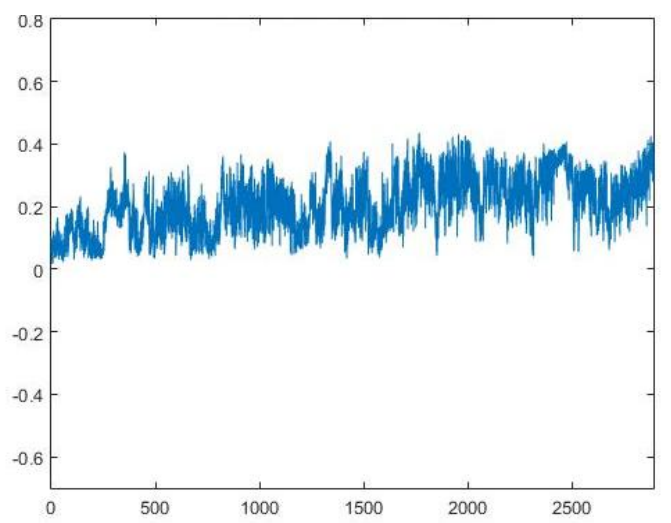

Figura 7 - Coeficiente de atrito pelo tempo, para o teste com óleo mineral (a), vegetal (b) e sem lubrificante (c) Fonte: Autores (2019).

Para a análise de viscosidade observou-se que o óleo de dendê e o mineral possui valores de Segundos Saybolt Universal (SSU) muito próximos quando trabalhado na maior temperatura, chegando a ter semelhança iguala a $86,2 \%$. Porém, para a temperatura de $40{ }^{\circ} \mathrm{C}$ essa diferença se distancia, chegando a aproximadamente $57,7 \%$.

Se tratando de valores de IV, o óleo de dendê é $150 \%$ maior que o óleo mineral, sendo mais eficiente que o óleo mineral em trabalhos de altas temperaturas. Esses fatos podem ser observados na Tabela 5.

Tabela 5 - Valores de SSU e IV para os óleos mineral e dendê

\begin{tabular}{cccc}
\hline Óleo & Temperatura & SSU & IV \\
\hline \multirow{2}{*}{ Mineral } & 40 & 484,3 & 37,76 \\
& 100 & 84,1 & \\
\hline \multirow{2}{*}{ Dendê } & 40 & 279,5 & 56,91 \\
& 100 & 72,5 & \\
\hline
\end{tabular}

Fonte: Autores (2019). 
Através do monitor de partículas ferrosas obteve-se o índice PQ (Quantificador de Partículas), apresentadas na Figura 8. Constatou-se que a quantidade de partículas ferrosas encontradas por meio do índice PQ ficaram em torno de 73,3\% esse valor é bom devido a precisão do instrumento que pode girar em torno de $\mathrm{PQ}=4$. A diferença na quantidade de partículas não é muito elevada. Tal resultado, porém pode ser atribuído à reduzida precisão do monitor de partículas para pequenas quantidades. Se o ensaio fosse feito em um tempo maior os valores ficariam melhores.

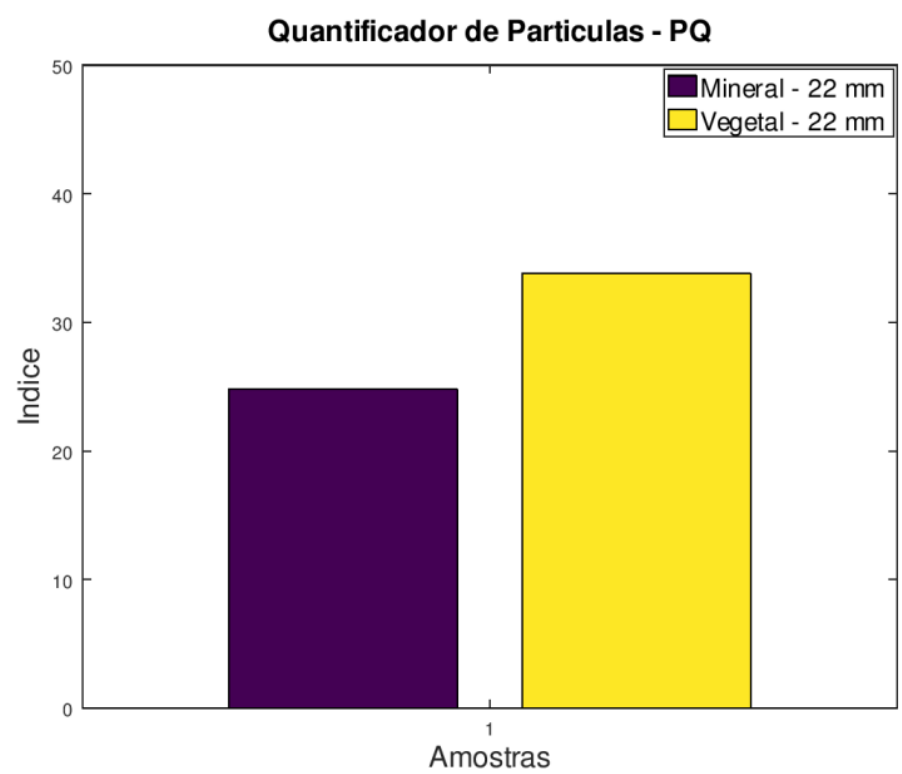

Figura 8 - Índice PQ Fonte: Autores (2019).

As fotografias obtidas por meio da análise dos ferrogramas resultantes do ensaio de RPD, representadas na Figura 9, mostram que a maioria das partículas de desgaste tem tamanhos normais menores que $20 \mu \mathrm{m}$, para esse tipo de partícula temos um desgaste por atrito simples.

De acordo com a literatura estudada de Hutchings (1992 apud MARU, 2003) as partículas que apresentam um desgaste severo podem ser observadas por suas morfologias oxidadas e disformes, além de partículas semelhantes a cavacos. Dessa forma, o fato dos ensaios deste estudo apresentarem uma pequena quantidade de partículas semelhantes às descritas pela literatura levam a conclusão de que as partículas observadas não caracterizem um desgaste severo. 

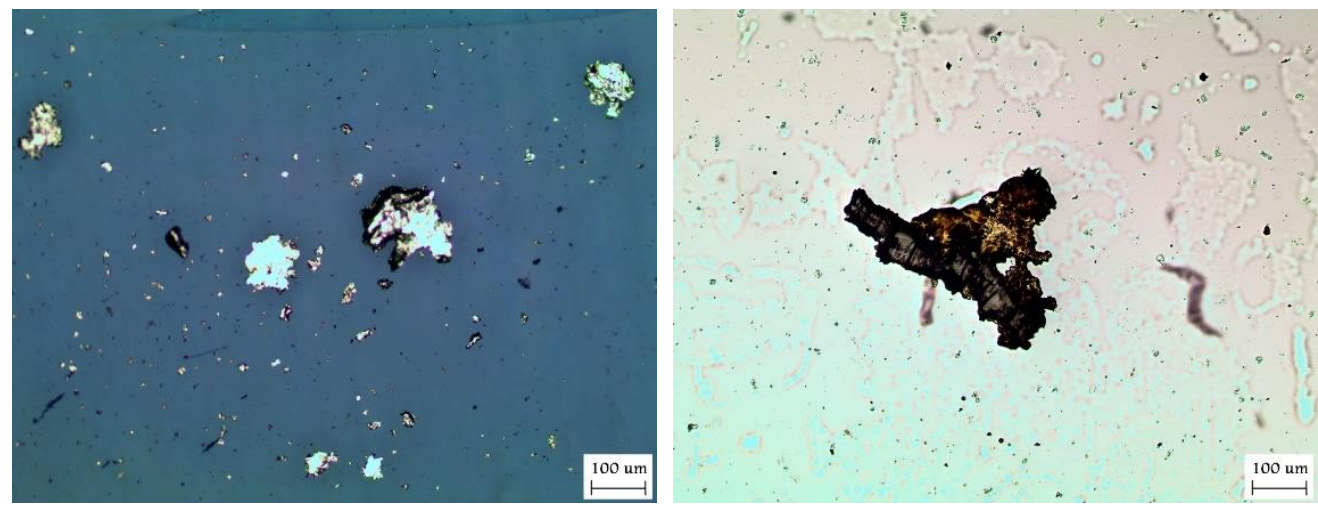

Figura 9 - Partículas de desgaste da amostra de raio $22 \mathrm{~mm}$ para o óleo mineral e vegetal (ampliação 100X) Fonte: Autores (2019).

\section{CONCLUSÃO}

Como apresentado, os lubrificantes vegetais têm um grande nicho a ser explorado por existirem poucas pesquisas e investimentos nessa área. A maior parte da pesquisa está na utilização do óleo como biodiesel e não como biolubrificante. Apesar do pouco investimento em escala nacional, os biolubrificantes são os lubrificantes do futuro por serem biodegradáveis, ecologicamente menos agressivo, além de se tratar de uma fonte “inesgotável” de matéria prima, ao contrário das bases minerais.

As análises de perda de massas bem como o monitoramento de partículas ferrosas mostraram que o óleo de dendê e o óleo mineral possuem resultados muito próximos quando analisados de uma visão mais ampla. Os coeficientes de atrito encontrados em ambos os óleos estão muito próximos quando observado nos primeiros 2000s de teste.

A variação do índice PQ entre os dois óleos ficaram bem próximos, mostrando que o óleo de dendê, sem nenhum aditivo, se comportou bem em comparação com o óleo mineral 15w-40 que é muito utilizado em carros de passeio.

Logo, pelos resultados obtidos, observou-se que o lubrificante vegetal, óleo de dendê, tem grande potencial para ser usado na substituição do óleo mineral. As análises realizadas nesse trabalho mostraram bons resultados, pois este estava livre de todo e qualquer tipo de tratamento a fim de torná-lo mais eficiente.

Em trabalhos futuros poderão ser analisados os resultados com óleos envelhecidos e com incremento de aditivos.

Sendo assim essa pesquisa espera poder divulgar os conhecimentos adquiridos sobre os óleos vegetais como forma de lubrificantes automotivos, de forma a incentivar novas pesquisas nessa área e quem sabe até um possível investimento de empresas interessadas. 


\title{
Viability analysis of the use of dende oil in automotive lubrication through the pin-on-disk test
}

\begin{abstract}
Alternatives that reduce the dependence of the world energy resources on mineral oil derivatives are increasingly discussed. There is a great deal of academic data relating pernicious consequences to the environment due to the oil industry and its refined components. The substitution of mineral based oils for the vegetable base is a measure following this trend. Vegetable oil is a biodegradable substance with a proven ability to decompose within an interval up to one year, making it a less toxic and environmentally aggressive product than mineral based ones. The vegetable oil chosen for this study is extracted from the palm tree (Elaeisguineenses). This oil is popularly known in Brazilian cuisine, mainly in Bahia. It is one of the most consumed vegetable oils in the world, soy and canola oils are in the upper positions. The objective of this study was to compare the properties and behaviors of $15 \mathrm{w}-40$ mineral oil against palm oil through a PIN-ON-DISK test with presence of the oil film. After the tests, the oil used was analyzed using spectrometric, ferrography, Saybolt's viscosity, ferrous debris monitor data and signals from the tribometer collected by the software. From the results obtained, it was observed that the palm oil lubricant has great potential to replace mineral oil. The data showed the real possibility of using palm oil without any additional treatment in order to make it more efficient, such as mixture of additives or artificial aging.
\end{abstract}

Keywords: Tribology. Vegetable lubricant. Wear.

\section{REFERÊNCIAS}

ACHCAR, Karina. Investigação da possibilidade de utilização de lubrificantes vegetais em motores de combustão interna: ensaios em equipamentos pin-on-disk. 2015. 112f. Dissertação (Mestrado em Engenharia Mecânica). Universidade Estadual Paulista Júlio de Mesquita Filho, Ilha Solteira, 2015.

ALVES, Fernando Ribeiro. Desenvolvimento de um tribômetro, tipo cilindro sob disco, para ensaios tribológicos em formulações com óleos vegetais. 2014. 133 f. Dissertação (Mestrado em Engenharia Mecânica) - Universidade Estadual Paulista Júlio de Mesquita Filho, Ilha Solteira, 2014.

ARAÚJO, L. A. de. Desenvolvimento de formulações cosméticas contendo óleos vegetais para proteção e reparação capilar. 2015. Dissertação (Mestrado em Medicamentos e Cosméticos) - Faculdade de Ciências Farmacêuticas de Ribeirão Preto, Universidade de São Paulo, Ribeirão Preto, 2015. doi:10.11606/D.60.2015.tde-04052015-154442.

BÍROVÁ, A.; PAVLOVIČOVÁ, A.; CVENROŁ, J.. Lubricating oils based on chemically modified vegetable oils. JOURNAL OF SYNTHETIC LUBRICATION, [S.I.], v. 18, n. 4, p.291-299, jan. 2002. Wiley. http://dx.doi.org/10.1002/jsl.3000180405 
CAMPESTRE; O óleo e o homem. Disponível em: http://www.campestre.com.br/o-oleo-ehomem/. Acesso em 15 de dezembro de 2016.

CANCIAM, César Augusto. Efeito da temperatura na viscosidade dinâmica dos óleos lubrificantes SAE 5W20, SAE 5W30 E SAE 5W40. Revista da Universidade Vale do Rio Verde, Três Corações, v. 11, n. 2, p.239-250, ago. 2013.

HENKES, Jairo Afonso; LEBID, Taras. Óleo de dendê na produção de biodiesel: um estudo de caso das vantagens e desvantagens econômica, ecológica e social da cultura desta oleaginosa para a produção de biodiesel. Revista Gestão \& Sustentabilidade Ambiental, Florianópolis, v. 4, n. 1, p. 392-415, 2015.

JOST, H. Peter. Lubrication (tribology) education and research. London: HMSO, 1966, p. 4.

MARU, Marcia Marie. Estudo do desgaste e atrito de um par metálico sob deslizamento lubrificado. 2003. 22 f. Tese (Doutorado em Engenharia Mecânica) - Universidade de São Paulo, São Paulo, 2003.

MELO, Maria Andrea Mendes Formiga. Avaliação das Propriedades de Óleos Vegetais visando a Produção de Biodiesel. 2010. 118 f. Dissertação (Mestrado em Química) Universidade Federal da Paraíba, João Pessoa, 2010.

NORTON, Robert Lloyd. Mancais de rolamento e lubrificação. In: NORTON, Robert Lloyd. Projeto de Máquinas: uma abordagem integrada. 4. ed. Rio de Janeiro: Bookman, 2013. p. 543-597.

OSAKI, Mauro; BATALHA, Mario Otavio. Produção de biodiesel e óleo vegetal no Brasil: realidade e desafio. Organizações Rurais \& Agroindustriais, v. 13, n. 2, p. 227-242, 2011.

RADI, Polyana Alves; SANTOS, Lúcia Vieira; BONETTI, Luiz Francisco; TRAVAAIROLDI, Vladimir J. Tribologia, conceitos e aplicações. In: ANAIS DO $13^{\circ}$ ENCONTRO DE INICIAÇÃO CIENTÍFICA E PÓS-GRADUÇÃO DO ITA (XIII ENCITA). XIII., São José dos Campos. Anais [...]. São José dos Campos: Instituto Tecnológico de Aeronáutica, 2007.

RAMOS, Luiz P. et al. Biodiesel: Raw Materials, Production Technologies and Fuel Properties. Revista Virtual de Química, [S.1.], v. 9, n. 1, p.317-369, 2017. Sociedade Brasileira de Química (SBQ). http://dx.doi.org/10.21577/1984-6835.20170020.

SECRETARIA DA EDUCAÇÃO DO ESTADO DO CEARÁ (SEDUC). Lubrificação industrial. Fortaleza, 2011. 69 p. Disponível em: https://www.seduc.ce.gov.br/wpcontent/uploads/sites/37/2011/10/mecanica_lubrificacao_industrial.pdf >. Acesso em: 15 dez. 2016.

SILVA, José André Cavalcanti da. Obtenção de um lubrificante biodegradável a partir de ésteres do biodiesel da mamona via catálise enzimática e estudos de estabilidades 
oxidativa e térmica. 2012. 188 f. Tese (Doutorado em Engenharia Química) - Universidade Federal do Rio de Janeiro, Rio de Janeiro, 2012.

SILVEIRA, J. L.; MACIEL, W. da C.; MOURA, A. S. da. Ensinando o estudo técnico e a averiguação da viscosidade rotulada de óleos lubrificantes comercialmente disponíveis: aplicação em motores de combustão interna e componentes mecânicos. In: CONGRESSO BRASILEIRO DE ENSINO DE ENGENHARIA, XXXII., 2004, Brasília. Anais... Brasilia: . 2004. p. 1 - 12.

SINATORA, Amilton. Tribologia: um resgate histórico e o estado da arte. 2005.Universidade de São Paulo, São Paulo, 2005.

SOUZA, Antônio Cirilo de. Fundamentos da mecânica automotiva. São Paulo: Senai SP, 2014.

STOETERAU, Rodrigo Lima. Tribologia. Florianópolis: UFSC, 2004.

TEXACO. Fundamentos de lubrificação automotiva. Rio de Janeiro: Texaco, 2005.

WHITBY, R. D. Understanding the global lubricants business : regional markets, economic issues and profitability. Oxford, 2005.

\section{DADOS DOS AUTORES}

Nome: Erikson Fabiano Moura Sousa Silva

E-mail: efmssilva@uesc.br

Currículo Lattes: http://lattes.cnpq.br/9656531765341368

Mestrado e graduação em Engenharia Mecânica pela Universidade Estadual Paulista Júlio de Mesquita Filho (UNESP-FEIS) - Campus Ilha Solteira, com ênfase na área de tribologia, manufatura aditiva e mecânica dos sólido. Atualmente é Professor Assistente "A" da Universidade Estadual de Santa Cruz (UESC). Tem experiência em Engenharia Mecânica, tribologia, análise de lubrificantes, análise estrutural por métodos de elementos finitos, vibração estrutural e projetos de sistemas mecânicos.

Nome: Sillas Oliveira Cezar

E-mail: sillas_cezar@hotmail.com

Currículo Lattes: http://lattes.cnpq.br/3363341279953312

Mestrando em Engenharia Mecânica pela Universidade Estadual Paulista (UNESP) com pesquisas na área de vibrações mecânicas e análises de sinais, pós-graduando em Engenharia de Segurança do Trabalho pela Universidade Candido Mendes e graduado em Engenharia Mecânica pela Universidade Estadual de Santa Cruz (UESC).

Nome: Aparecido Carlos Gonçalves

E-mail: aparecido.carlos@unesp.br

Currículo Lattes: http://lattes.cnpq.br/7516385196117516 
Doutorado em Engenharia Mecânica, mestrado em Engenharia Metalúrgica [S. Carlos] e graduação em Engenharia Mecânica pela Universidade de São Paulo (USP). Atualmente é professor adjunto da Universidade Estadual Paulista Júlio de Mesquita Filho e assessor dos periódicos - Journal of Materials Science - Journal of Thermoplastic Composite Materials Industrial Lubrication and Tribology. Tem experiência na área de Engenharia Mecânica, com ênfase em Máquinas, Motores e Equipamentos, atuando principalmente nos seguintes temas: análise de óleos, análise de vibrações, manutenção preditiva, análise de partículas e projetos de sistemas mecânicos. Coordenou projetos de Pesquisas da FINEP, CNPq (Universal Faixa C), FAPESP (3), Fundunep (Fundação para o Desenvolvimento da Unesp), Fepisa (Fundação de Ensino, Pesquisa e Extensão de Ilha Solteira) e Proex (Pro-reitoria de Extensão Universitária da Unesp). Atualmente coordena um projeto de pesquisa FAPESP. Orientador de Doutorado.

Nome: Paulo Roberto Rocha Filho Matos

E-mail: paulomatosf@gmail.com

Currículo Lattes: http://lattes.cnpq.br/3730910467689517

Graduação em Engenharia Mecânica pela Universidade Estadual de Santa Cruz (UESC), durante a graduação fez intercambio internacional em 2014 na Auburn University - Auburn, EUA, como bolsista CAPES. Atualmente é técnico de operação na Petrobras.

Nome: Gabriel Alves Costa

E-mail: gabrielalves.alvescosta@ gmail.com

Currículo Lattes: http://lattes.cnpq.br/4300451274491738

Doutorando em Engenharia Mecânica na área de projeto mecânico, mestrado em Engenharia Mecânica pela Faculdade de Engenharia de Bauru - Universidade Estadual Paulista. Bacharel em Engenharia Mecânica pela Universidade Estadual de Santa Cruz. 